\title{
47 Consecutive Cases of Pipeline Flex Flow Diversion Utilizing a Novel Large-Bore Intracranial Intermediate Catheter: Nuances and Institutional Experience with the Syphontrak
}

\author{
Li-Mei Lin $^{a} \quad$ Bowen Jiang $^{\mathrm{b}}$ Matthew T. Bender ${ }^{\mathrm{b}}$ Erick M. Westbroek ${ }^{\mathrm{b}}$ \\ Jessica K. Campos ${ }^{b}$ Rafael J. Tamargo ${ }^{c}$ Judy Huang ${ }^{c}$ Alexander L. Coon ${ }^{c}$ \\ Geoffrey P. Colby ${ }^{\text {d }}$ \\ ${ }^{a}$ Department of Neurosurgery, University of California, Irvine School of Medicine, UC Irvine \\ Medical Center, Orange, CA, USA; ${ }^{b}$ Department of Neurosurgery, Johns Hopkins University \\ School of Medicine, Baltimore, MD, USA; ' ${ }^{C}$ Department of Neurosurgery, Johns Hopkins \\ University School of Medicine, The Johns Hopkins Hospital, Baltimore, MD, USA; \\ ${ }^{\mathrm{d}}$ Department of Neurosurgery, University of California, Los Angeles, Los Angeles, CA, USA
}

\section{Keywords}

Aneurysm - Endovascular · Flow diversion · Intermediate catheter · Distal intracranial catheter · Pipeline embolization device

\begin{abstract}
Background: The increasing complexity of modern neurointerventions has necessitated a shift in intracranial access techniques towards more robust distal support platforms. Here we present our experience with the Syphontrak Support Catheter (Codman Neuro, Raynham, MA, USA) in the triaxial platform for the implantation of the second-generation Pipeline Flex embolization device (PED Flex; Medtronic Neurovascular, Irvine, CA, USA). Methods: We retrospectively identified patients who underwent PED Flex treatment utilizing the Syphontrak at a single institution. The procedural data collected included parent artery tortuosity, patient demographics, aneurysm characteristics, other equipment utilized, and catheter-related complications. Results: A total of 47 consecutive aneurysm flow diversions were successfully performed using the Syphontrak. The patients' age ranged from 25 to 80 years (mean $57.3 \pm 11.6$ ) and $85 \%$ were women. The average aneurysm size was $4.8 \pm 2.7 \mathrm{~mm}$ (range 2-14). All cases were in the anterior circulation, with $6(12 \%)$ aneurysms located beyond the internal carotid artery termination. Significant cervical carotid tortuosity was present in $23 \%$ (11/47) of the cases and moderate-to-severe cavernous tortuosity (cavernous grade $\geq 2$ ) in $51 \%(24 / 47)$ of the cases. The mean fluoroscopy time was $36.6 \pm 14.8 \mathrm{~min}$. In 12/47 cases (26\%), vasospasm
\end{abstract}


prophylaxis with intra-arterial verapamil infusion was performed. The Syphontrak was tracked to the intended distal position in all cases, with a $100 \%$ technical success of PED Flex implantation. Forty-six (98\%) of the 47 patients were discharged home after an average length of stay of 1.38 days. No iatrogenic catheter-related vessel injury occurred. Transient, minor neurological morbidity occurred in 3 cases (6\%) and 1 patient had a minor ischemic event (NIHSS score $<4)$ in the periprocedural period. Conclusion: The Syphontrak is a new large-bore, multi-durometer intermediate catheter (IC) designed for use in modern neurointerventional procedures. We have shown its utility in 47 successful cases of PED Flex flow diversion of a wide range of complexity. The IC provides robust and atraumatic distal intracranial access while also providing an enhanced image quality with its large $0.060^{\prime \prime}$ inner diameter.

(c) 2018 S. Karger AG, Basel

\section{Introduction}

As endovascular therapies for intracranial aneurysms continue to evolve, the need for more stable and reliable access support systems to the cerebral vasculature has become increasingly important. The access techniques of modern neurointerventional procedures for many operators have shifted from biaxial to triaxial systems. Flow diverters such as the Pipeline Flex embolization device (PED Flex; Medtronic Neurovascular) and the Surpass flow diverter (Stryker Neurovascular, Fremont, CA, USA), as well as flow disruptors such as the Woven EndoBridge Device (MicroVention/Sequent Medical, Tustin, CA, USA), have necessitated this shift. In conjunction with the development and introduction of these new devices, a new category of intracranial catheters, distal intracranial catheters (DICs) or intermediate catheters (ICs), has emerged to provide robust distal intracranial support. This support is vitally important for the delivery of flow diverters [1] and flow disruptors, which utilize larger microcatheters than the traditional microcatheters for the delivery of coils or adjunctive devices [1].

DICs were designed with the flexibility to navigate the distal intracranial circulation safely while providing support for enhanced microcatheter control [1]. Initial catheters such as the Outreach and Neuron were successful in navigating into the proximal intracranial vasculature, inching the guide catheter support from a cervical location closer to distal intracranial locations [2-4]. With the introduction of the Navien (Medtronic Neurovascular), a 5or 6-Fr intracranial catheter support in distal intracranial locations of both the anterior and posterior circulations became routine [5-7]. The AXS Catalyst 5 (Stryker Neurovascular) is a next-generation multi-durometer DIC incorporating design modifications to maximize robust support and atraumatic navigation [8].

The Syphontrak (Codman Neuro, Raynham, MA, USA) is the newest addition to the DIC family of catheters for neurointervention. In this report we present our initial experiences using the Syphontrak in PED Flex flow diversion cases.

\section{Methods}

Patient Selection

We retrospectively reviewed a prospective, single-center aneurysm database identifying all patients undergoing Pipeline Flex embolization for treatment of cerebral aneurysms using the Syphontrak from August 2016 (first availability of the catheter at our institution) to June 2017.

All procedures were performed at either the Johns Hopkins Hospital or the Johns Hopkins Bayview Medical Center (both in Baltimore, MD, USA). 


\begin{tabular}{l|l}
\hline DOI: $10.1159 / 000486538$ & $\begin{array}{l}\text { (c) 2018 S. Karger AG, Basel } \\
\text { www.karger.com/ine }\end{array}$ \\
\hline
\end{tabular}

Lin et al.: 47 Consecutive Cases of Pipeline Flex Flow Diversion Utilizing a Novel Large-Bore Intracranial Intermediate Catheter

Table 1. Patient demographics

Total cases, $n$
Mean age \pm SD (range), years
Female sex, $n(\%)$
Previously treated, $n(\%)$
$\quad$ Clip
$\quad$ Coil
Flow diversion
Wrap
Mean size \pm SD (range), mm
Small, $n(\%)$
Large, $n(\%)$
Giant, $n(\%)$
47

$57.3 \pm 11.6(25-80)$

$40(85)$

$10(21)$

$1(2)$

$6(13)$

$2(4)$

$1(2)$

$4.83 \pm 2.73(2-14)$

$45(96)$

$2(4)$

$0(0)$

\section{Data Collection and Analysis}

Data on patient demographics, aneurysm size, vessel tortuosity, vasodilator use, fluoroscopy time, procedural equipment, technical details, and periprocedural complications related to the catheter access were collected. Factors assessed for proximal tortuosity included cervical internal carotid artery (ICA) tortuosity (defined as a $90^{\circ}$ turn, hairpin turn, or corkscrew loop) and cavernous ICA grade [9]. The data are presented as counts and means. Statistical analysis of counts was done using $\chi^{2}$ tests and statistical analysis of means was conducted using the Student $t$ test or one-way analysis of variance.

Endovascular Procedure

The patients were preoperatively treated with $325 \mathrm{mg}$ aspirin and $75 \mathrm{mg}$ clopidogrel daily for at least 1 week prior to the treatment. Platelet inhibition testing was not routinely performed. Systemic anticoagulation with heparin was done during the embolization. Through an 8-Fr femoral short sheath, a triaxial system was used for all procedures, consisting of an 8-Fr-long guide sheath, a DIC, and a $0.027^{\prime \prime}$-inner diameter (ID) microcatheter.

Details regarding the PED Flex procedure have been previously described [10-12]. In general, the intended target of the Syphontrak position was just proximal to the aneurysm. For instance, in the case of a paraophthalmic ICA aneurysm, the intended catheter target would be the anterior genu/horizontal cavernous segment of the ICA. The Syphontrak would then be withdrawn proximally as needed during PED deployment. Although the catheter targets were established at the time of the case, the overall data analysis for this study was done retrospectively.

\section{Results}

\section{Patient and Aneurysm Characteristics}

During the time course of the institutional study (August 2016 to June 2017), 47 consecutive patients with cerebral aneurysms were treated with a PED Flex using the Syphontrak catheter (Table 1) by the senior author. Forty (85\%) of the 47 patients were female. The mean patient age was $57.3 \pm 11.6$ years (range $25-80$ ). Ten patients $(21 \%)$ had previously treated aneurysms, with coiling in 6 cases, clipping in 1 case, flow diversion in 2 cases, and cotton wrapping in 1 case. The average aneurysm size was $4.8 \pm 2.7 \mathrm{~mm}$, with a range of 2-14 $\mathrm{mm}$. Forty-five (96\%) of the 47 aneurysms were classified as small $(2-10 \mathrm{~mm})$ and the remainder were considered large (11-24 $\mathrm{mm})$.

All cases of Syphontrak utilization were in the anterior circulation (Table 2). The most common sites of PED Flex deployment were along the ICA. Paraophthalmic and ophthalmic aneurysms accounted for 33/47 cases (70\%). There were 5 cases of supraclinoid/posterior communicating aneurysms (11\%), 1 petrous aneurysm (2\%), 1 cavernous aneurysm (2\%), and 1 aneurysm at the ICA termination (2\%). In addition to ICA aneurysms, $3(6 \%)$ anterior communicating artery region aneurysms and $3(6 \%)$ middle cerebral artery aneurysms were treated. 
Table 2. Aneurysm location

\begin{tabular}{l|l}
\hline DOI: 10.1159/000486538 & $\begin{array}{l}\text { @ } 2018 \text { S. Karger AG, Basel } \\
\text { www.karger.com/ine }\end{array}$ \\
\hline Lin et al.: 47 Consecutive Cases of Pipeline Flex Flow Diversion Utilizing a Novel \\
Large-Bore Intracranial Intermediate Catheter
\end{tabular}

\begin{tabular}{lc}
\hline Anterior circulation & $47(100 \%)$ \\
Internal carotid & $41(85 \%)$ \\
$\quad$ Cervical & $0(0 \%)$ \\
Petrous & $1(2 \%)$ \\
Cavernous & $1(2 \%)$ \\
Ophthalmic/paraophthalmic & $33(70 \%)$ \\
Supraclinoid/posterior communicating & $5(11 \%)$ \\
Internal carotid artery termination & $1(2 \%)$ \\
Anterior cerebral & $3(6 \%)$ \\
Anterior communicating artery/A1-2 & $3(6 \%)$ \\
Middle cerebral & $3(6 \%)$ \\
M1 & $0(0 \%)$ \\
M2 & $1(2 \%)$ \\
Bifurcation & $2(4 \%)$ \\
Posterior circulation & $0(0 \%)$ \\
\hline
\end{tabular}

Table 3. Vessel characteristics and Syphontrak distal access catheter positions

\begin{tabular}{lc}
\hline $\begin{array}{l}\text { Cervical carotid tortuosity } \\
\text { Cavernous ICA grade }\end{array}$ & $11(23 \%)$ \\
Ia & $12(26 \%)$ \\
Ib & $11(23 \%)$ \\
II & $11(23 \%)$ \\
III & $9(19 \%)$ \\
IV & $4(9 \%)$ \\
Syphontrak position & \\
Cervical ICA & $0(0 \%)$ \\
Petrous ICA & $1(2 \%)$ \\
Proximal cavernous ICA & $22(47 \%)$ \\
Distal cavernous ICA & $19(40 \%)$ \\
Supraclinoid ICA & $3(6 \%)$ \\
M1 & $2(4 \%)$ \\
\end{tabular}

ICA, internal carotid artery.

\section{Equipment Utilized}

The Syphontrak (Codman Neuro) was the DIC utilized in the triaxial system for all 47 cases (Fig. 1). The 6-Fr-long guide sheaths used included the AXS Infinity 0.088" (Stryker Neurovascular) in 46 cases and the Neuron Max 0.088" (Penumbra, Alameda, CA, USA) in 1 case. The VIA27 (MicroVention/Sequent Medical) was the PED Flex delivery microcatheter used in 46 cases and the Phenom 27 microcatheter was used in 1 case (Medtronic Neurovascular).

\section{Vessel Tortuosity and Catheter Positions}

Significant cervical ICA tortuosity defined as a $90^{\circ}$ turn, hairpin turn, or corkscrew loop was encountered in 11/47 (23\%) of the cases (Table 3). Figure 2 demonstrates selected examples of cervical tortuosity successfully navigated by the Syphontrak. The cavernous carotid grade was also assigned to each case according to a previously published classification system [9]. This anatomical grading system has been established as a predictor of PED Flex case complexity. Minimal cavernous ICA tortuosity (types IA and IB) was observed in $23 / 47$ (49\%) of the cases, while moderate-to-severe cavernous ICA tortuosity (types II-IV) was present in $24 / 47$ cases (51\%). Figure 3 demonstrates an example of intracranial cavernous tortuosity easily navigated with the Syphontrak without vessel distortion. In all but one case, the Syphontrak was positioned beyond the petrous segment of the ICA. The most 


\section{Interventional \\ Neurology}

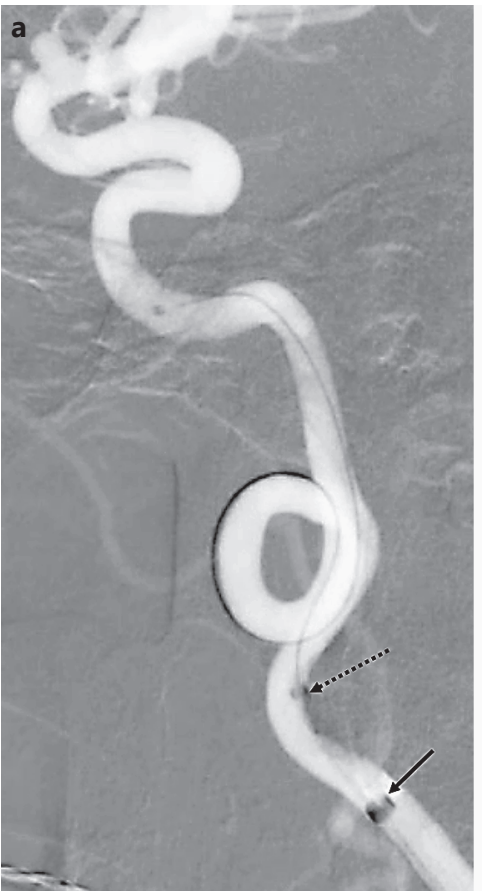

\begin{tabular}{l|l}
\hline Intervent Neurol 2018;7:153-163 \\
\hline DOI: 10.1159/000486538 & $\begin{array}{l}\text { @ 2018 S. Karger AG, Basel } \\
\text { www.karger.com/ine }\end{array}$ \\
\hline
\end{tabular}

Lin et al.: 47 Consecutive Cases of Pipeline Flex Flow Diversion Utilizing a Novel Large-Bore Intracranial Intermediate Catheter
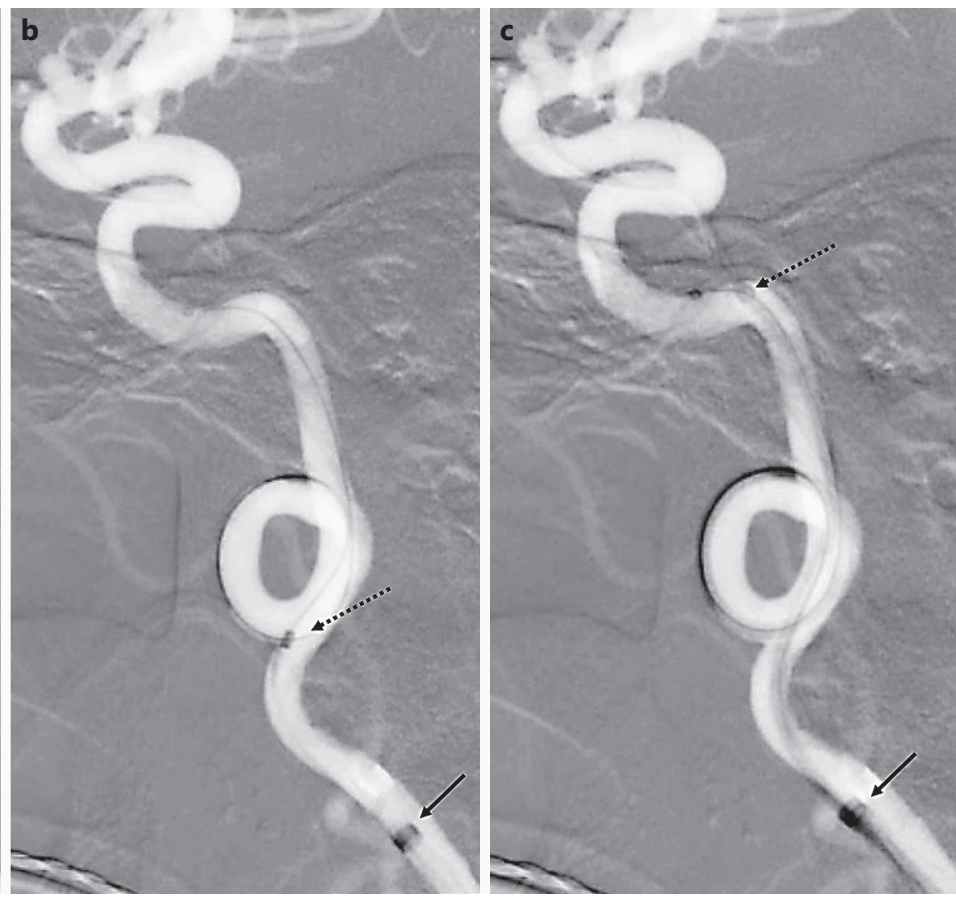

Fig. 1. Enhanced trackability and stability of the Syphontrak catheter in cervical tortuosity of the anterior circulation. a-c Road map fluoroscopy demonstrating sequential images of Syphontrak (dashed arrow) tracking through a hairpin loop in the proximal cervical internal carotid artery tortuosity with little-to-no retrograde displacement of the AXS Infinity guide sheath (solid arrow) or the VIA 0.027 " microcatheter.
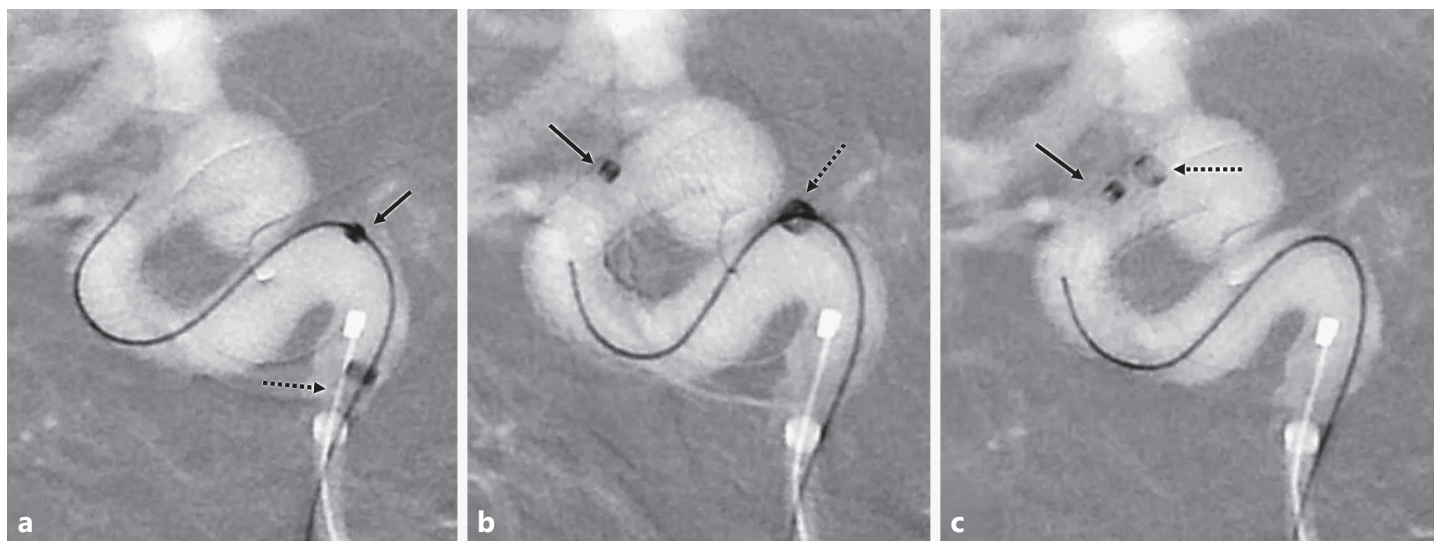

Fig. 2. Trackability and stability of the Syphontrak catheter through a high-grade cavernous internal carotid artery (ICA) anatomy. a-c Road map fluoroscopy demonstrating sequential images of Syphontrak (dashed arrow) tracking through a tortuous grade III cavernous ICA over a VIA $0.027^{\prime \prime}$-inner diameter (solid arrow) microcatheter and a Fathom $0.016^{\prime \prime}$ wire.

common positions of the Syphontrak for intracranial support were as follows: proximal cavernous (defined as within the posterior genu or horizontal segments; $n=22 ; 47 \%$ ), distal cavernous (defined as the anterior genu; $n=19 ; 40 \%$ ), and supraclinoid ( $n=3 ; 6 \%$ ). In 2 cases, the Syphontrak was tracked into the proximal M1 for treatment of distal middle cerebral artery aneurysms. 
Interventional

Neurology

Table 4. Procedural details

\begin{tabular}{|c|c|c|}
\hline \multicolumn{3}{|c|}{ Intervent Neurol 2018;7:153-163 } \\
\hline DOI: $10.1159 / 000486538$ & \multicolumn{2}{|c|}{$\begin{array}{l}\text { ( } 2018 \text { S. Karger AG, Basel } \\
\text { www.karger.com/ine }\end{array}$} \\
\hline \multicolumn{3}{|c|}{$\begin{array}{l}\text { Lin et al.: } 47 \text { Consecutive Cases of Pipeline Flex Flow Diversion Utilizing a Novel } \\
\text { Large-Bore Intracranial Intermediate Catheter }\end{array}$} \\
\hline \multicolumn{2}{|c|}{ Mean fluoroscopy time \pm SD (range), min } & $\begin{array}{l}36.6 \pm 14.8 \\
(14.5-79.5)\end{array}$ \\
\hline \multicolumn{2}{|c|}{ Mean radiation exposure \pm SD (range), $m G y$} & $\begin{array}{l}1,876 \pm 913 \\
(449-4,797)\end{array}$ \\
\hline \multicolumn{2}{|c|}{ Successful PED implantation, $n(\%)$} & $47(100)$ \\
\hline \multicolumn{2}{|c|}{ Mean number of PED per case \pm SD (range) } & $\begin{array}{l}1.28 \pm 0.45 \\
(1-2)\end{array}$ \\
\hline \multicolumn{3}{|c|}{ Guide sheath used, $n(\%)$} \\
\hline \multicolumn{2}{|c|}{ AXS Infinity } & $46(98)$ \\
\hline \multicolumn{2}{|c|}{ Neuron Max } & $1(2)$ \\
\hline \multicolumn{3}{|c|}{$0.027^{\prime \prime}$ microcatheter used, $n(\%)$} \\
\hline \multicolumn{2}{|c|}{ VIA } & $46(98)$ \\
\hline \multicolumn{2}{|l|}{ Phenom } & $1(2)$ \\
\hline \multicolumn{2}{|c|}{ Intra-arterial verapamil, $n(\%)$} & $12(26)$ \\
\hline \multicolumn{2}{|c|}{ Adjunct coil deployment, $n(\%)$} & $3(6)$ \\
\hline \multicolumn{2}{|c|}{ Balloon angioplasty, $n(\%)$} & $12(26)$ \\
\hline \multicolumn{2}{|c|}{ In situ thrombosis/ReoPro, $n(\%)$} & $3(6)$ \\
\hline
\end{tabular}

PED, Pipeline Flex embolization device.
Fig. 3. Contrast injection through the Syphontrak catheter $(0.060 "$ inner diameter) prior to Pipeline Flex embolization device (PED) deployment. Pre-PED deployment digital subtraction angiography and native view injections from the Syphontrak in a 72-yearold patient with incidentally discovered up- and down-projecting ophthalmic segment internal carotid artery aneurysms.

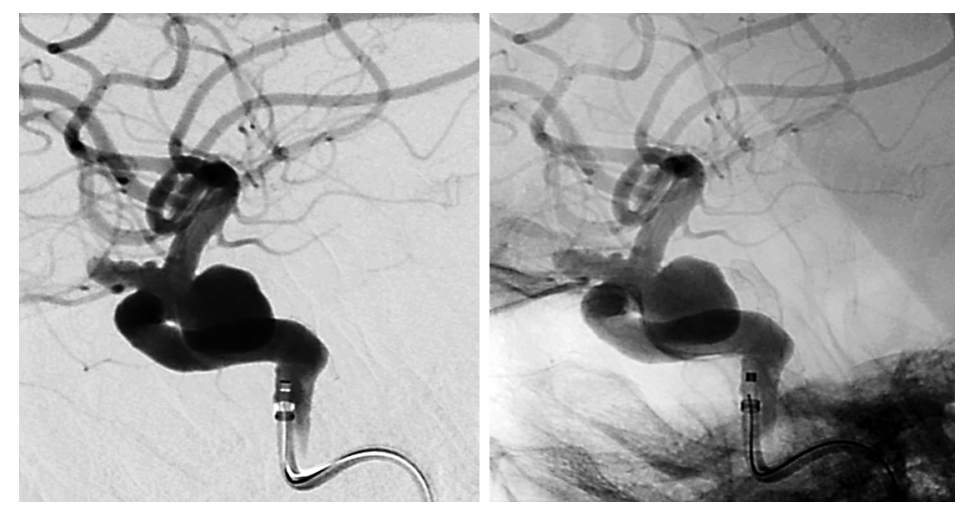

\section{Procedural Characteristics and Complications}

All 47 cases were completed with successful PED Flex implantation. The procedural details are highlighted in Table 4. In 1 case, a $4 \times 12 \mathrm{~mm}$ PED Flex was foreshortened too much during deployment and no longer covered the neck of the intended aneurysm; as such, this device was thought to be of insufficient length and thus was recaptured completely and removed. A new $4 \times 14 \mathrm{~mm}$ device was then introduced and deployed without incident. The mean fluoroscopy time was $36.6 \pm 14.8 \mathrm{~min}$ and the mean radiation exposure was $1,876 \pm 913$ mGy. Verapamil infusion was administered intra-arterially for vasospasm prophylaxis or treatment in $12 / 47$ cases (26\%). Balloon angioplasty was utilized in 12 cases (26\%) to improve vessel wall apposition of the flow diverter after deployment. In addition, coil embolization was performed in 3 cases at the time of PED Flex implantation. Intra-arterial abciximab was administered in 3 cases of in situ thrombosis due to platelet aggregation immediately after PED Flex deployment.

The majority of the patients were discharged home (98\%) after an average length of stay of 1.4 days (range 1-5) (Table 5). There were no access-related complications such as iatrogenic dissection or groin hematoma. There were no periprocedural mortalities, intracranial hemorrhage, subarachnoid hemorrhage, or major strokes in this cohort. One minor stroke and 3 transient deficits were noted. 
Table 5. Outcomes and procedural complications
Lin et al.: 47 Consecutive Cases of Pipeline Flex Flow Diversion Utilizing a Nove Large-Bore Intracranial Intermediate Catheter

$\begin{array}{lc}\text { Mean length of stay } \pm \text { SD (range), days } & 1.38 \pm 0.795(1-5) \\ \text { Discharge to home, } n(\%) & 46(98) \\ \text { Mortality, } n(\%) & 0(0) \\ \text { SAH, } n(\%) & 0(0) \\ \text { Major stroke, } n(\%) & 0(0) \\ \text { Minor stroke, } n(\%) & 1(2) \\ \text { Dependent ICH, } n(\%) & 0(0) \\ \text { Remote ICH, } n(\%) & 0(0) \\ \text { Transient deficit, } n(\%) & 3(6) \\ \text { Cranial nerve palsy, } n(\%) & 0(0) \\ \text { Iatrogenic dissection, } n(\%) & 0(0) \\ \text { Groin hematoma, } n(\%) & 0(0)\end{array}$

SAH, subarachnoid hemorrhage; ICH, intracranial hemorrhage.

Table 6. Comparison of 5-Fr distal intracranial catheter specifications

\begin{tabular}{lllll}
\hline & Syphontrak & Navien 058 & Cat 5 & Sofia \\
\hline OD proximal/distal, inch & $0.076 / 0.069$ & 0.070 & $0.073 / 0.069$ & 0.068 \\
ID proximal/distal, inch & $0.062 / 0.060$ & 0.058 & 0.058 & 0.055 \\
Distal flexible length, cm & 18 & 8 & 5 & 17 \\
Working lengths available, cm & $105 ; 115 ; 125$ & $105 ; 115 ; 125 ; 130$ & 115 or 132 & 115 or 125 \\
\hline
\end{tabular}

OD, outer diameter; ID, inner diameter.

\section{Discussion}

In this report, we describe our experience with the Syphontrak catheter in treatment of anterior circulation cerebral aneurysms by Pipeline flow diversion. Despite the presence of cervical ICA tortuosity in 23\% (11/47) and moderate-to-severe cavernous ICA tortuosity (cavernous ICA grades II-IV) in 51\% (24/27) of the cases, the Syphontrak catheter navigated successfully to the intended locations and PED Flex implantation was completed in all cases. Intra-arterial verapamil infusion for treatment or prophylaxis of catheter-related vasospasm was only utilized in $26 \%(12 / 47)$ of the cases.

The flow diversion revolution with the PED Flex has changed the practice paradigm for many cerebral aneurysm treatments [13] and with it the common catheter components of the coaxial support system [14]. The larger 0.027 "-ID delivery microcatheters for flow diverter deployment and the relatively increased push and pull forces used to deploy such devices have led to the routine use of a new class of support catheters called ICs or DICs. The Navien catheter was introduced close to the launch of the PED in the USA, and since then several other ICs/DICs have emerged, including the AXS Catalyst 5, Sofia, and now the Syphontrak [1, $5,8]$. These 5 -Fr catheters were designed for use within a triaxial platform system with a long guide sheath [15]. Table 6 compares the general specifications for several 5-Fr DICs commonly used in PED Flex deployment.

The Syphontrak catheter is the newest of the available DICs. This catheter is designed with a proximal stainless steel braid that ends in a nitinol coil for a combination of proximal strength and distal flexibility. The distal flexible zone is $18 \mathrm{~cm}$ in length. The true distal tip is rounded and tapered to facilitate atraumatic movement. On the proximal end, the acrylic Luer lock hub is short, giving an increasing functional microcatheter working length, particularly when combined with the included short rotating hemostatic valve. 

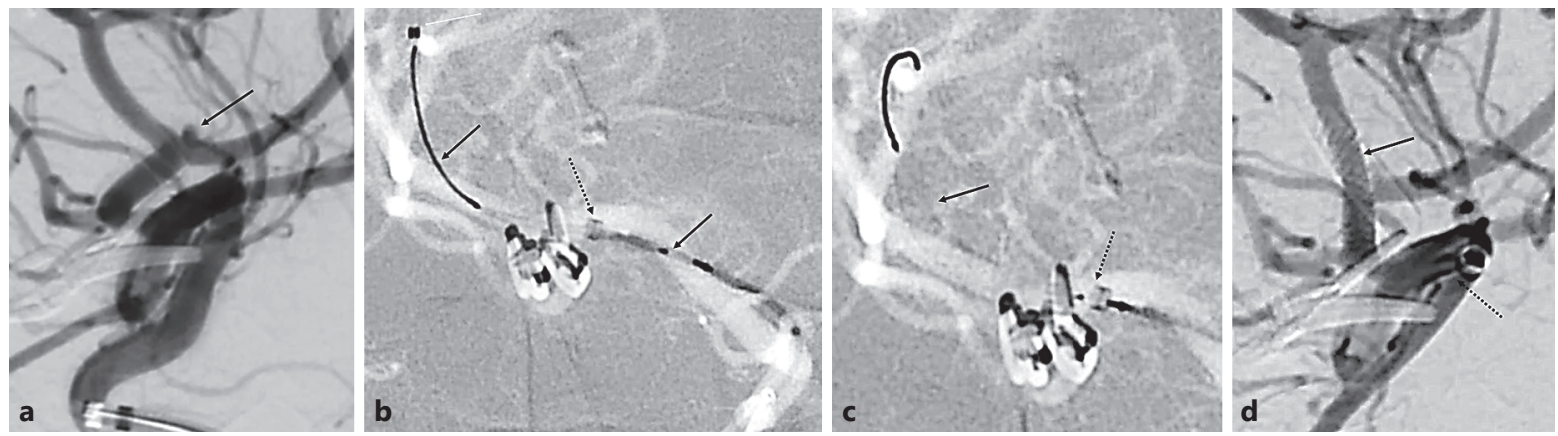

Fig. 4. Pipeline embolization of a right M2 aneurysm in a 50-year-old patient showing Syphontrak tracking into the M1 segment. a Preembolization digital subtraction angiogram showing a small-blister right M2 aneurysm (arrow). b Syphontrak catheter advanced into the distal M1 (dotted arrow) with the predeployed Pipeline Flex embolization device (PED; solid arrows) tracking through the VIA27 microcatheter (white arrow). c The Syphontrak (dotted arrow) maintains a stable position in the distal M1 during PED deployment (solid arrow). d Post-deployment injection through the Syphontrak (tip; dotted arrow) showing adequate PED wall apposition (solid arrow) and no in-stent thrombosis with aneurysmal dome contrast stasis.

The Syphontrak outer diameter (OD) is $6 \mathrm{Fr}\left(0.076^{\prime \prime}\right)$ proximally and tapers to $5 \mathrm{Fr}$ $\left(0.069^{\prime \prime}\right)$ distally. The larger OD allows for added stability and pushability of the catheter. Despite the larger overall OD, the Syphontrak remained easy to navigate to distal intracranial positions in each of the cases of this series. We routinely positioned the Syphontrak by tracking it over a $0.027^{\prime \prime}$ microcatheter and a $0.016^{\prime \prime}$ microwire. This method, along with the rounded distal tip of the Syphontrak, helps reduce "step-off" and allows for successful atraumatic navigation through the vasculature. We routinely positioned the Syphontrak in the distal cavernous ICA and even tracked the catheter to the supraclinoid ICA and M1 without evidence of vessel injury or significant flow-limiting vasospasm (Fig. 4).

The main feature that distinguishes the Syphontrak from the other DICs currently available on the market is its ID. The ID of the Syphontrak is $0.062^{\prime \prime}$ proximally and $0.060^{\prime \prime}$ distally. Compared to the other 5-Fr distal ICs/DICs, the Syphontrak provides the largest ID with its $0.060^{\prime \prime}$ specification (Table 6). This extra space allows for an improved flush rate and better contrast injection through the DIC. The better contrast injections allow for enhanced digital subtraction angiography runs, roadmaps, and "puffing" to check vessel patency and flow (Fig. 3). For aneurysm treatments requiring a larger delivery microcatheter, such as the Surpass platform, this larger ID provides a significant advantage [16].

In addition to serving as a support system, the DIC can also be used as an instrument or advanced technique for augmenting PED Flex deployment $[8,11]$. As with the Navien and Catalyst 5, the Syphontrak has the trackability and pushability for such advanced maneuvers despite its overall larger OD. For example, the Syphontrak can be tracked over the $0.027^{\prime \prime}$ microcatheter with ease to bump and foreshorten the proximal end of the PED Flex in order to improve vessel wall apposition if needed. The DIC also can be tracked over the microcatheter into the PED Flex for endoluminal access. Endoluminal access is advantageous in cases needing multi-device deployments or balloon angioplasty to postprocess a malapposed PED Flex implant. Furthermore, the larger ID of the Syphontrak facilitates intra-DIC deployment of the proximal PED Flex in cases with a tortuous cavernous anatomy [11].

We have previously reported our institutional experience with the AXS Catalyst 5 [8] and Navien DICs [5]. Table 7 highlights the case complexity of the comparison between those that 
Table 7. Comparison of institutional experience with 5-Fr Navien, Cat 5, and Syphontrak catheters

\begin{tabular}{lcccc}
\hline & $\begin{array}{l}\text { Syphontrak } \\
(n=47)\end{array}$ & $\begin{array}{l}\text { Navien 058 } \\
(n=78)\end{array}$ & $\begin{array}{l}\text { Cat 5 } \\
(n=110)\end{array}$ & $p$ value \\
\hline Cervical tortuosity, \% & 23 & 44 & 26 & 0.01779 \\
Cavernous ICA grade, \% & & & 75 & 0.4070 \\
$\quad$ I-II & 72 & 58 & 25 & 0.4070 \\
$\quad$ III-IV & 28 & 42 & $31.9 \pm 23.5$ & 0.0009 \\
Mean fluoroscopy time \pm SD, min & $36.6 \pm 14.8$ & $47.8 \pm 39.3$ & 14 & 0.00191 \\
Verapamil use, \% & 26 & 3.8 & & 0.8289 \\
Distal position of catheter, \% & 0 & & 0 & $<0.0001$ \\
$\quad$ Cervical ICA & 2 & 30 & 52 & 0.2260 \\
$\quad$ Petrous ICA & 47 & 62 & 26 & $<0.0001$ \\
$\quad$ Proximal cavernous ICA & 40 & 4 & 18 & 0.0019 \\
$\quad$ Distal cavernous ICA & 6 & 2 & 4 & 0.9315 \\
$\quad$ Supraclinoid ICA & 4 & 1 & 0 & 1.00 \\
$\quad$ Other & 0 & 0 & & \\
Vessel injury/dissection, \% & & & & \\
\hline
\end{tabular}

ICA, internal carotid artery.

utilized the Syphontrak and those that used the other DICs. There was a statistically significant difference in the proportion of cases with cervical tortuosity treated with the Navien (44\%) compared to the Syphontrak (23\%) or Catalyst 5 (26\%), which is likely a reflection of our earlier experience with the PED in mostly "on-label" cases of older patients with a more complex proximal anatomy. There was no statistically significant difference in cavernous ICA grading between the three cohorts. Compared to our earlier experiences with the Navien, both the Catalyst 5 and the Syphontrak cases utilized statistically significantly less fluoroscopy time, despite similar numbers and sizes of Pipeline devices. Verapamil was utilized in $26 \%$ of the cases with the Syphontrak series compared to $3.8 \%$ in the Navien series and $14 \%$ in the Catalyst 5 series. The increased use of verapamil was multifactorial. This reflects our changing institutional practice patterns to utilize IA vasodilation prophylactically rather than as a reactive measure to vasospasm. For the Syphontrak, prophylactic IA verapamil was frequently used, knowing that the catheter's OD is larger and that the catheter tip is to be intentionally advanced to very distal locations. Despite the increased usage of IA verapamil, there were no catheter-related complications and no significant changes in overall procedural complications and outcomes. This finding again highlights that despite the fact that the Syphontrak has a larger OD, it still can be safely navigated to more distal locations without increased adverse complications.

The primary limitations of the Syphontrak arise from its larger proximal OD. Although this feature of the catheter adds support and pushability, it can reduce the quality of contrast injections through the long guide sheath when the Syphontrak is fully advanced or "hubbed." Additionally, the larger OD of the Syphontrak excludes its use in cases requiring direct 5-Fr access, where the DIC is advanced directly through a short 5-Fr sheath. Direct carotid punctures for severe proximal tortuosity and posterior circulation cases needing radial or brachial access fall into this category [17]. In these circumstances, the Navien 058 remains the catheter of choice. The general limitation of this series is the mostly retrospective data collection and review. 


\section{Conclusion}

The Syphontrak is the newest addition to the DICs for advanced neurointervention. Compared to other 5-Fr distal catheters, the Syphontrak provides similar atraumatic navigation and robust intracranial support while also providing a larger ID $\left(0.060^{\prime \prime}\right)$ for improved image visualization.

\section{Statement of Ethics}

All individual identifying information, including age and sex, have been meticulously anonymized in the manuscript to achieve appropriate anonymity.

\section{Disclosure Statement}

A.L.C. is a proctor for the Woven EndoBridge device (Sequent Medical, Aliso Viejo, CA, USA), a proctor for the Surpass device (Stryker Neurovascular) and a consultant for Stryker Neurovascular, a proctor for the PED (Medtronic Neurovascular) and a consultant for Medtronic, a proctor for the FRED device (MicroVention) and a consultant for MicroVention, and a consultant for InNeuroCo (Sunrise, FL, USA). G.P.C. is a consultant for Codman Neuro and MicroVention and participates in clinical trials for Medtronic and Stryker Neurovascular. L.-M.L. is a proctor for the PED (Medtronic Neurovascular) and a consultant for MicroVention and participates in a clinical trial for Stryker Neurovascular. The other authors have no conflict of interest. No author received any financial support in conjunction with the generation of this paper.

\section{Author Contributions}

L.-M.L., G.P.C., and B.J. drafted the manuscript and critically revised it for important intellectual content. M.T.B., J.K.C., E.M.W., and B.J. assisted with the data collection and analysis. G.P.C. performed the treatment procedures and assisted in critically revising the manuscript. E.M.W., M.T.B., J.H., A.L.C., and R.J.T. crucially reviewed the important intellectual content of the manuscript. All authors read and approved the final manuscript.

\section{References}

1 Lin LM, Colby GP, Bender MT, Xu R, Huang J, Tamargo RJ, Coon AL: Use of the 0.027-inch VIA microcatheter for delivery of Pipeline Flex: a technical note. J Neurointerv Surg 2017;9:689-693.

2 Chaudhary N, Pandey AS, Thompson BG, Gandhi D, Ansari SA, Gemmete JJ: Utilization of the Neuron 6 French 0.053 inch inner luminal diameter guide catheter for treatment of cerebral vascular pathology: continued experience with ultra distal access into the cerebral vasculature. J Neurointerv Surg 2012;4:301-306.

3 Hauck EF, Tawk RG, Karter NS, Binning MJ, Khalessi AA, Natarajan SK, Hopkins LN, Levy EI, Siddiqui AH: Use of the outreach distal access catheter as an intracranial platform facilitates coil embolization of select intracranial aneurysms: technical note. J Neurointerv Surg 2011;3:172-176.

4 Turk A, Manzoor MU, Nyberg EM, Turner RD, Chaudry I: Initial experience with distal guide catheter placement in the treatment of cerebrovascular disease: clinical safety and efficacy. J Neurointerv Surg 2013;5:247-252.

5 Colby GP, Lin LM, Huang J, Tamargo RJ, Coon AL: Utilization of the Navien distal intracranial catheter in 78 cases of anterior circulation aneurysm treatment with the Pipeline embolization device. J Neurointerv Surg 2013;5(suppl 3):iii16-iii21.

6 Lin LM, Colby GP, Huang J, Tamargo RJ, Coon AL: Ultra-distal large-bore intracranial access using the hyperflexible Navien distal intracranial catheter for the treatment of cerebrovascular pathologies: a technical note. J Neurointerv Surg 2014;6:301-307.

7 Jindal G, Giacon L, Iyoha M, Miller T, Aldrich F, Simard M, Shivashankar R, Gandhi D: Navien catheter experience in neuroendovascular interventions. Interv Neuroradiol 2017;23:551-555. 
8 Colby GP, Lin LM, Xu R, Beaty N, Bender MT, Jiang B, Huang J, Tamargo RJ, Coon AL: Utilization of a novel, multidurometer intracranial distal access catheter: nuances and experience in 110 consecutive cases of aneurysm flow diversion. Interv Neurol 2017;6:90-104.

9 Lin LM, Colby GP, Jiang B, Uwandu C, Huang J, Tamargo RJ, Coon AL: Classification of cavernous internal carotid artery tortuosity: a predictor of procedural complexity in Pipeline embolization. J Neurointerv Surg 2015;7: 628-633.

10 Colby GP, Lin LM, Caplan JM, Jiang B, Huang J, Tamargo RJ, Coon AL: Immediate procedural outcomes in 44 consecutive Pipeline Flex cases: the first North American single-center series. J Neurointerv Surg 2016;8: 702-709.

11 Lin LM, Colby GP, Jiang B, Nundkumar N, Huang J, Tamargo RJ, Coon AL: Intra-DIC (distal intracranial catheter) deployment of the Pipeline embolization device: a novel rescue strategy for failed device expansion. J Neurointerv Surg 2016;8:840-846.

12 Lin LM, Colby GP, Kim JE, Huang J, Tamargo RJ, Coon AL: Immediate and follow-up results for 44 consecutive cases of small $(<10 \mathrm{~mm})$ internal carotid artery aneurysms treated with the pipeline embolization device. Surg Neurol Int 2013;4:114.

13 Jiang B, Paff M, Colby GP, Coon AL, Lin LM: Cerebral aneurysm treatment: modern neurovascular techniques. Stroke Vasc Neurol 2016;1:93-100.

14 Aguilar-Salinas P, Brasiliense LB, Gonsales D, Mitchell B, Lima A, Sauvageau E, Hanel R: Evaluation of Pipeline Flex delivery system for the treatment of unruptured aneurysms. Expert Rev Med Devices 2016;13:885-897.

15 Lin LM, Bender MT, Colby GP, Beaty NB, Jiang B, Campos JK, Huang J, Tamargo RJ, Coon AL: Use of a nextgeneration multi-durometer long guide sheath for triaxial access in flow diversion: experience in 95 consecutive cases. J Neurointerv Surg 2018;10:137-142.

16 Colby GP, Lin LM, Caplan JM, Jiang B, Michniewicz B, Huang J, Tamargo RJ, Coon AL: Flow diversion of large internal carotid artery aneurysms with the surpass device: impressions and technical nuance from the initial North American experience. J Neurointerv Surg 2016;8:279-286.

17 Lin LM, Colby GP, Jiang B, Nundkumar N, Huang J, Tamargo RJ, Coon AL: Percutaneous direct carotid approach using the hyperflexible large-bore Navien distal intracranial catheter for treatment of anterior circulation aneurysms. EJMINT Original Article 2014:1436000154. 